\title{
Recombinant C1 Inhibitor P5/P3 Variants Display Resistance to Catalytic Inactivation by Stimulated Neutrophils
}

\author{
Eric Eldering, Cécile C.M. Huijbregts, Jan H. Nuijens, Arthur J. Verhoeven, * and C. Erik Hack \\ Departments of Autoimmune Diseases and *Blood Cell Chemistry, Central Laboratory of the Netherlands Red Cross Blood Transfusion \\ Service; and Laboratory for Experimental and Clinical Immunology, University of Amsterdam, 1066 CX Amsterdam, The Netherlands
}

\begin{abstract}
Proteolytic inactivation of serine protease inhibitors (serpins) by neutrophil elastase (HNE) is presumed to contribute to the deregulation of plasma cascade systems in septic shock. Here, we report a supplementary approach to construct serpins, in our case $\mathrm{C} 1$ inhibitor, that are resistant to catalytic inactivation by HNE. Instead of shifting the specificity of $\alpha 1$-antitrypsin towards the proteases of the contact activation and complement systems, we attempted to obtain a $\mathrm{Cl}$ inhibitor species which resists proteolytic inactivation by $\mathrm{HNE} .12$ recombinant $\mathrm{Cl}$ inhibitor variants were produced with mainly conservative substitutions at the cleavage sites for HNE, 440-Ile and/or 442Val. Three variants significantly resisted proteolytic inactivation, both by purified HNE, as well as by activated neutrophils. The increase in functional half-life in the presence of FMLPstimulated cells was found to be 18 -fold for the $440-\mathrm{Leu} / 442-$ Ala variant. Inhibitory function of these variants was relatively unimpaired, as examined by the formation of stable complexes with C1s, $\beta$-Factor XIIa, kallikrein, and plasmin, and as determined by kinetic analysis. The calculated association rate constants $\left(k_{\text {on }}\right)$ were reduced twofold at most for $\mathrm{C1s}$, and appeared unaffected for $\beta$-Factor XIIa. The effect on the $\boldsymbol{k}_{\text {on }}$ with kallikrein was more pronounced, ranging from a significant ninefold reduction to an unmodified rate. The results show that the reactive centre loop of $\mathrm{Cl}$ inhibitor can be modified towards decreased sensitivity for nontarget proteases without loss of specificity for target proteases. We conclude that this approach extends the possibilities of applying recombinant serpin variants for therapeutic use in inflammatory diseases. (J. Clin. Invest. 1993.91:1035-1043.) Key words: serine protease inhibitor $\cdot$ inflammation $\cdot$ complement $\bullet$ elastase $\bullet$ metalloprotease
\end{abstract}

\section{Introduction}

The serine protease inhibitors (serpins) present in human plasma serve important functions as specific inhibitors of the coagulation, contact activation, fibrinolytic, and complement cascades (1). Serpins share a common mechanism by present-

Address correspondence to Eric Eldering, Central Laboratory of the Netherlands Red Cross Blood Transfusion Service, Department of Autoimmune Diseases, Plesmanlaan 125, 1066 CX Amsterdam, The Netherlands. Jan H. Nuijens' current address is GenePharming Europe B.V., Einsteinweg 5, 2333 CC Leiden, The Netherlands.

Received for publication 24 July 1992 and in revised form 12 October 1992

J. Clin. Invest.

(C) The American Society for Clinical Investigation, Inc.

0021-9738/93/03/1035/09 \$2.00

Volume 91, March 1993, 1035-1043 ing an exposed loop as substrate for target proteases, and proteolytic attack results in the formation of very stable, essentially irreversible complexes. Remarkably, the reactive center loop of several serpins, notably antithrombin III, $\alpha 2$-antiplasmin, and $\mathrm{Cl}$ inhibitor, contains additional cleavage sites for neutrophil elastase (2-4). It was proposed that the susceptibility of these serpins for catalytic inactivation serves a physiological purpose by allowing localized proteolytic activity at inflammatory sites (5). In accord with this concept, stimulated neutrophils release oxygen radicals and metalloproteases (6-8), which in concert inactivate $\alpha 1$-antitrypsin, thereby creating a microenvironment in which human neutrophil elastase (HNE) ${ }^{1}$ is no longer inhibited. These events presumably contribute to tissue destruction in local inflammatory reactions and to dysregulation of plasma cascade systems in systemic inflammation, such as septic shock, in which massive neutrophil activation occurs.

Recombinant serpins derived from $\alpha 1$-antitrypsin are inherently insensitive to inactivation by HNE and have been tested for therapeutic use in the shock syndromes (9-11). However, the $\alpha$ l-antitrypsin background may impose restrictions on their specificity; for example, none of the described variants is an efficient inhibitor of the complement proteases $\mathrm{Cl} r$ and $\mathrm{C} 1 \mathrm{~s}$ $(11,12)$. $\mathrm{Cl}$ inhibitor is a plasma glycoprotein with an apparent relative molecular mass of 104,000 in SDS gels, but the actual relative molecular mass has been shown to be $\sim 76,000$ (13). Genetic defiency of $\mathrm{Cl}$ inhibitor, resulting from either quantitative or structural defects, is the cause for the disease hereditary angioedema $(14,15)$. Because $\mathrm{Cl}$ inhibitor is the most effective inhibitor in vivo of the complement proteases $\mathrm{Clr}$ and $\mathrm{Cls}$, and the contact activation proteases Factor XIla and kallikrein (16-18), all of which have been implicated to contribute to septic shock $(9,19,20)$, we decided to investigate whether its sensitivity for proteolytic inactivation by $\mathrm{HNE}$ could be reduced without loss of function.

\section{Methods}

Enzymes and reagents. Enzymes for recombinant DNA techniques were obtained as described previously, as were $\mathrm{Cl}$ inhibitor, $\mathrm{Cls}, \beta$ Factor XIIa, and kallikrein (all human) (reference 21 and references therein). Human plasmin was a kind gift of Dr. Colin Longstaff ( National Institute for Biological Standards and Control, South Mimms, Hertfordshire, UK). Human neutrophil elastase was purchased from Elastin Products (Pacific, MO). Chromogenic substrates S-2314 and S-2302 were obtained from Kabi AB (Stockholm, Sweden). Heparin grade I (181 U/mg, molecular weight range 15,000-18,000), FMLP,

1. Abbreviations used in this paper: DPI, diphenyleneiodonium; HNE, human neutrophil elastase; [I], inhibitor concentration; $k_{\text {obs }}$, apparent rate constant; $k_{\text {off }}$, dissociation rate constant; $k_{\text {on }}$, association rate constant; PMA, phorbol myristate acetate; $\mathrm{rCl}$ inh, recombinant $\mathrm{Cl}$ inhibitor; wt, wild type. 
cytochalasin B, phorbol myristate acetate (PMA), and 1,10-phenanthroline were obtained from Sigma Immunochemicals (St. Louis, MO). $\left[{ }^{35} \mathrm{~S}\right]$ methionine (specific activity $>37 \mathrm{TBq} / \mathrm{mmol}$ ) was purchased from the Radiochemical Centre (Amersham, UK).

Mutagenesis, expression and purification of recombinant $\mathrm{Cl}$ inhibitor. A 300-bp EcoRI-SstI fragment from the COS-1 expression vector $\mathrm{pCl}$ inhibitor (22) was subcloned in M13mp18-mp4 and used as template for mutagenesis according to published procedures $(21,23)$. Antisense primers coding for the desired mutations at P5 (440-Ile) and P3 (442-Val) were synthesized on DNA synthesizer (type 381 A; Applied Biosystems, Warrington, UK). Because we wanted to preserve the inhibitory functions of $\mathrm{Cl}$ inhibitor, most substitutions were semiconservative in nature and maintained the medium-sized aliphatic side chain of the wild type P5(Ile) and P3(Val) residues. Mutations at P3 only were constructed with the following oligomers (mismatched bases are underlined):

\section{P3-Ala: 5'-GGTGCGGGCGGCAGAGATGG-3'}

P3-Gly: 5'-GGTGCGGGCTCCAGAGATGG-3'

P3-Arg: 5'-GGGTGCGGGCTCTAGAGATGGCG-3'

P3-Leu: 5'-GCGGGCCAGAGAGATGG-3'

\section{P3-Thr: 5'-GGGTGCGGGCGGTAGAGATGGCG-3'}

Mutagenesis at both P5 and P3 was performed with a degenerate oligomer coding for combinations of conservative amino acid substitutions, with the following sequence:

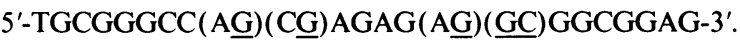

12 clones coding for substitutions at P5 (440-Ile) and / or P3 (442Val) were identified; 3A, 3G, 3R, 3L, 3T, 5L3A, 5L 3L, 5L3V, 5V 3A, $5 \mathrm{~V} 3 \mathrm{~L}, 5 \mathrm{~A} 3 \mathrm{~A}$, and $5 \mathrm{~V}$ (numbers refer to $\mathrm{P} 5$ or $\mathrm{P} 3$ positions in the reactive center of $\mathrm{Cl}$ inhibitor, amino acids are designated by standard one-letter code). The EcoRI-SstI fragment was reinserted in the expression vector and, after large scale plasmid preparation, double strand sequencing was performed to ensure that no other mutations had occurred. Transfection of the COS-1 cell line was performed as described (22), and the serum-free conditioned medium was assayed for the presence of $\mathrm{Cl}$ inhibitor antigen by a RIA using a solid-phase monoclonal antibody (19). The amino acid changes did not affect detection in this assay (not shown). Expression levels varied between 1 and $3 \mu \mathrm{g} / \mathrm{ml}$. Recombinant $\mathrm{Cl}$ inhibitor ( $\mathrm{rCl}$ inh) variants were purified by lectinaffinity chromatography on jacalin agarose (Pierce Chemical Co., Rockford, IL) (24), as described in detail previously (21).

Radioimmunoassays. RIA procedures to determine binding activity of $\mathrm{Cl}$ inhibitor to $\beta$-Factor XIIa and kallikrein were developed as described for C1s $(19,21,22)$. Purified proteases were coupled to Sepharose 4B (Pharmacia, Uppsala, Sweden ). Experiments were performed by incubating serial dilutions of transfection media with protease-sepharose for $4 \mathrm{~h}$ at room temperature, followed by quantitation of bound recombinant $\mathrm{Cl}$ inhibitor as described $(19,22)$. Susceptibility to purified $\mathrm{HNE}$ was determined by incubating transfection media containing $100 \mathrm{ng} \mathrm{rCl}$ inh with serial dilutions of HNE (total vol $200 \mu$ ) for $3 \mathrm{~h}$ at $37^{\circ} \mathrm{C}$ in $200 \mathrm{mM} \mathrm{NaCl}, 50 \mathrm{mM}$ Tris- $\mathrm{HCl}, \mathrm{pH}$ 8. $\alpha 1$-Antitrypsin was then added in a fourfold molar excess over $\mathrm{HNE}$ and residual $\mathrm{Cl}$ inhibitor function was determined by the RIA with solid phase Cls. The supernatant of human neutrophils $\left(6 \times 10^{6} / \mathrm{ml}\right)$ primed with cytochalasin B $(5 \mu \mathrm{g} / \mathrm{ml}, 5 \mathrm{~min})$ and activated with $1 \mu \mathrm{M}$ FMLP contained 5 $\mu \mathrm{g} / \mathrm{ml} \mathrm{HNE}$. Serial dilutions were incubated with $100 \mathrm{ng} \mathrm{rCl}$ inh in reaction mixtures $(100 \mu \mathrm{l})$ containing $10 \mathrm{mM}$ sodiumphosphate, 150 $\mathrm{mM} \mathrm{NaCl}, 0.1 \%$ wt/vol Tween-20, $10 \mathrm{mM}$ Tris- $\mathrm{HCl}, \mathrm{pH} 7.4$, and further treated as with purified HNE.

Electrophoretic studies with purified ${ }^{35} S-r C 1$ inh. Transfected subconfluent COS- 1 cells were metabolically labeled with $50 \mu \mathrm{Ci} / \mathrm{ml}\left[{ }^{35} \mathrm{~S}\right]-$ methionine for $4 \mathrm{~h}$ and chased overnight, as described $(21) .{ }^{35} \mathrm{~S}-\mathrm{rCl}$ inh was affinity purified with jacalin-agarose, with minor modifications of a published procedure (21). The jacalin eluate was dialyzed against $200 \mathrm{mM} \mathrm{NaCl}, 50 \mathrm{mM}$ Tris- $\mathrm{HCl}, \mathrm{pH} 8,0.1 \%$ wt / vol Tween-20, and BSA was added to a concentration of $100 \mu \mathrm{g} / \mathrm{ml}$. The concentration of purified ${ }^{35} \mathrm{~S}-\mathrm{rCl}$ inh variants was about $1 \mu \mathrm{g} / \mathrm{ml} .10 \mathrm{ng}$ of purified ${ }^{35} \mathrm{~S}$-rCl inh was incubated with a 50 -fold molar excess of $\beta$-Factor XIIa, a 20 -fold excess of kallikrein or a 10-fold excess of plasmin for $1 \mathrm{~h}$ at $37^{\circ} \mathrm{C}$. These protease/inhibitor ratios were determined to be optimal for visualization of complexes of $\mathrm{rCl}$ inh wild type $(\mathrm{wt})$ in preliminary experiments. Reactions were terminated by addition of nonreducing sample buffer followed by SDS-PAGE on $7.5 \%$ gels and fluorography. Serial dilutions of HNE (final concentration 0.6-40 nM) were incubated with $20 \mathrm{ng}$ of purified ${ }^{35} \mathrm{~S}-\mathrm{rCl}$ inhibitor for $2 \mathrm{~h}$ at $37^{\circ} \mathrm{C}$ in $200 \mathrm{mM} \mathrm{NaCl}, 50 \mathrm{mM}$ Tris- $\mathrm{HCl}, \mathrm{pH} 8$. HNE was then inhibited by addition of $100 \mathrm{ng}$ eglin C (Ciba-Geigy, Basel, Switzerland). The reaction mixture was split into two portions and nonreducing sample buffer was either directly added or after incubation with $200 \mathrm{ng} \mathrm{C1s}$ for $1 \mathrm{~h}$ at $37^{\circ} \mathrm{C}$. Densitometric scanning of autoradiograms was done (Quickscan; Helena Laboratories, Beaumont, TX), and results were calculated on an integrator (Shimadzu, Kyoto, Japan).

Proteolytic inactivation of $\mathrm{Cl}$ inhibitor by activated neutrophils. Purified human neutrophils were obtained as described (25) and suspended in incubation medium $(132 \mathrm{mM} \mathrm{NaCl}, 6 \mathrm{mM} \mathrm{KCl}, 1 \mathrm{mM}$ $\mathrm{MgSO}_{4}, 1.2 \mathrm{mM}$ potassium phosphate, $20 \mathrm{mM}$ Hepes, $\mathrm{pH} 7.4$ ) supplemented with glucose $(5.5 \mathrm{mM}), \mathrm{CaCl}_{2}(1 \mathrm{mM})$, and BSA $(0.5 \% \mathrm{wt} /$ $\mathrm{vol}$ ) at a final concentration of $2 \times 10^{6}$ cells $/ \mathrm{ml}$ at $37^{\circ} \mathrm{C}$. Recombinant $\mathrm{Cl}$ inhibitor used for these experiments was purified as described (21), and suspended in PBS, pH 7.4, 0.01\% wt/vol Tween-20, $0.5 \% \mathrm{wt} / \mathrm{vol}$ $\mathrm{BSA}$, and added $(5 \mu \mathrm{g} / \mathrm{ml}$ final concentration $)$ before priming the cells with cytochalasin B $(5 \mu \mathrm{g} / \mathrm{ml})$ and stimulation with FMLP $(1 \mu \mathrm{M})$. In some experiments, cells were stimulated with PMA $(100 \mathrm{ng} / \mathrm{ml})$. At timed intervals, samples $(100 \mu \mathrm{l})$ were withdrawn and added to $10 \mu \mathrm{l}$ of a mixture of inhibitors (final concentrations: $10 \mu \mathrm{M}$ eglin C, $10 \mathrm{mM}$ EDTA, $2 \mathrm{mM}$ 1,10-phenanthroline, $1 \mu \mathrm{M}$ methionine). Zero timepoints were taken just before addition of FMLP. After collection of all samples, cells were removed by centrifugation, and $80 \mu \mathrm{l}$ of the supernatant was incubated with $20 \mu \mathrm{l}$ of $\mathrm{Cls}(20 \mu \mathrm{g} / \mathrm{ml})$ for $1 \mathrm{~h}$ at $37^{\circ} \mathrm{C}$. Residual Cls activity was quantitated ( Twinreader; Titertek, Elfab Oy, Finland) after addition of the chromogenic substrate S-2314 to $1 \mathrm{mM}$. The change in absorbance at $405 \mathrm{~nm}$ of the zero time points was taken as $100 \% \mathrm{Cl}$ inhibitor activity, and subsequent timepoints were calculated with reference to this value and $0 \% \mathrm{Cl}$ inhibitor value in wells with only $\mathrm{Cl}$ s. Preliminary experiments established that the starting $\mathrm{Cl}$ inhibitor (variant) concentration inhibited $80-90 \%$ of C1s activity, and that no reduction in $\mathrm{Cl}$ inhibitor activity occurred when cells were not stimulated.

Kinetic studies. Kinetic analysis was done as described (21). Briefly, inhibition of $\mathrm{Cls}$ by plasma $\mathrm{Cl}$ inhibitor and purified recombinant P5/P3 variants was monitored by the method of progress curves (26). Changes in absorbance at $405 \mathrm{~nm}$ were recorded for up to $12 \mathrm{~h}$ and fitted to the integrated rate equation for slow binding inhibition $A$ $=v_{\mathrm{s}} t+\left(v_{\mathrm{o}}-v_{\mathrm{s}}\right)\left(1-e^{-\mathrm{kobs} t}\right) / k_{\mathrm{obs}}+A_{\mathrm{o}}$, where $A$ is absorbence at 405 $\mathrm{nm}, v_{\mathrm{s}}$ is the final steady state rate, $t$ is time, and $v_{\mathrm{o}}$ is the initial rate, and $k_{\text {obs }}$ is the apparent rate constant, by nonlinear regression analysis (Enzfitter; Elsevier, London). Plots of $k_{\text {obs }}$ vs. [I] (inhibitor concentration ) were found to be straight lines, indicating a simple one-step reversible reaction for complex formation over the concentration range of inhibitor used for these experiments (see Results). Consequently, the association rate constant $\left(k_{\mathrm{on}}\right)$ could be calculated from the relationship $k_{\text {obs }}=k_{\text {off }}+k_{\text {on }}[\mathrm{I}] /\left(1+[\mathrm{S}] / K_{\mathrm{m}}\right)$, where $k_{\text {off }}$ is the dissociation rate constant. Experiments were performed in $10 \mathrm{mM}$ sodium phosphate, $150 \mathrm{mM} \mathrm{NaCl}, 50 \mathrm{mM}$ Tris- $\mathrm{HCl}, \mathrm{pH} 8$ containing $0.1 \% \mathrm{wt} / \mathrm{vol}$ Tween-20, $0.02 \% \mathrm{wt} / \mathrm{vol} \mathrm{NaN}_{3}$ and $2 \mathrm{mM} \mathrm{S}-2314\left(K_{\mathrm{m}} 0.8 \mathrm{mM}\right)$, at $37^{\circ} \mathrm{C}$ under mineral oil. The effect of heparin on the reaction was determined by adding $\mathrm{C} 1 \mathrm{~s}$ together with heparin (final concentrations $2 \mathrm{nM}$ and $0.1-100 \mathrm{U} / \mathrm{ml}$, respectively) to solutions containing $\mathrm{rCl}$ inhibitor (final concentrations 20-30 nM) and buffer. Results were analyzed as described above. The $k_{\text {on }}$ for $\beta$-Factor XIIa and kallikrein were determined under pseudo-first order conditions as described ( 17 , 21, 27). 
Table I. Effect of Amino Acid Substitutions at Reactive Center Positions P5 and P3 in CI Inhibitor on Complex Formation with Target Proteases $(A)$ and the Proteolytic Inactivation by Purified HNE or the Supernatant of Activated Neutrophils (B)

\begin{tabular}{|c|c|c|c|c|c|c|}
\hline $\mathrm{rCl}$ Inhibitor: & wt & $3 \mathbf{L}$ & $3 \mathbf{R}$ & $5 \mathrm{~V} 3 \mathrm{~A}$ & $5 \mathrm{~L} 3 \mathrm{~L}$ & $5 \mathrm{~L} 3 \mathrm{~A}$ \\
\hline \multicolumn{7}{|c|}{$A$ Complex formation (percentage compared to wild type) } \\
\hline Cls & 100 & $87 \pm 3$ & $66 \pm 5$ & $88 \pm 6$ & $73 \pm 3$ & $127 \pm 6$ \\
\hline$\beta$-FXIIa & 100 & $57 \pm 4$ & $35 \pm 10$ & $119 \pm 8$ & $46 \pm 2$ & $83 \pm 8$ \\
\hline kallikrein & 100 & $59 \pm 5$ & $21 \pm 1$ & $49 \pm 4$ & $68 \pm 4$ & $42 \pm 2$ \\
\hline \multicolumn{7}{|c|}{$B$ HNE susceptibility (nanograms of HNE or dilution of PMN supernatant) } \\
\hline HNE experiment 1 & 25 & 8 & 63 & 31 & 125 & 250 \\
\hline HNE experiment 2 & 31 & 8 & 63 & 45 & 150 & 250 \\
\hline PMN supernatant experiment 1 & $1: 64$ & $1: 128$ & $1: 16$ & $1: 64$ & $1: 8$ & $<1: 8$ \\
\hline PMN supernatant experiment 2 & $1: 64$ & $1: 128$ & $1: 16$ & $1: 64$ & $1: 8$ & $<1: 8$ \\
\hline PMN supernatant experiment 3 & $1: 64$ & $1: 64$ & $1: 16$ & $1: 64$ & $1: 8$ & $1: 4$ \\
\hline
\end{tabular}

$(A)$ The ability of $\mathrm{rC} 1$ inhibitor $\mathrm{P} 5 / \mathrm{P} 3$ variants to bind to sepharose-coupled $\mathrm{C} 1 \mathrm{~s}$, $\beta$-Factor XIla, or kallikrein was determined with RIAs. Results are expressed as percentage of complex formation compared to $\mathrm{rCl}$ inhibitor-wt, which is set at $100 \%$. Data represent averages $\pm \mathrm{SD}$ of at least two separate experiments. $(B)$ Twofold serial dilutions of purified HNE or of the supernatant of activated neutrophils (PMNs) were incubated for $3 \mathrm{~h}$ at $37^{\circ} \mathrm{C}$ with single volumes of transfection media containing $\mathrm{rCl}$ inhibitor variants. HNE was then inhibited by adding $\alpha 1$-antitrypsin and residual $\mathrm{rCl}$ inhibitor activity was subsequently determined towards $\mathrm{Cls}$ as in $\mathrm{A}$. Binding to $\mathrm{C}$ 1s-sepharose of untreated samples was set at $100 \%$. Results of separate experiments are expressed as nanograms of purified HNE or the dilution of neutrophil supernatant necessary to cause $>90 \%$ loss of inhibitory function compared to untreated samples.

\section{Results}

$12 \mathrm{rCl}$ inh variants were produced that contain substitutions at the inactivating cleavage sites for HNE, 440-Ile (P5) and 442-Val (P3) (3). To prevent laborious purification and kinetic analyses of all variants, an initial evaluation of inhibitory function and HNE resistance was performed with solid phase target proteases, as described in Methods. Previously, we have shown that this type of assay, which can be directly applied to transfection medium, correlates well with chromogenic assays for $\mathrm{Cl}$ inhibitor in plasma (19) and kinetic analysis for recombinant P1 variants (21). Data from five relevant $\mathrm{rCl}$ inh-P5/ P3 variants, as obtained in the initial screening, are summarized in Table I. Inhibitory function, as determined by binding to solid phase proteases, was affected to various degrees. Conservative changes generally did not affect binding, whereas the nonconservative changes $3 \mathrm{R}$, or $3 \mathrm{G}$ (not shown), reduced complex-formation with $\beta$-Factor XIIa and kallikrein to $>40 \%$ compared to wt $C 1$ inhibitor. HNE resistance was tested both with the purified protease and with supernatant of activated neutrophils. $\mathrm{rCl}$ inh variants were incubated with increasing concentrations of $\mathrm{HNE}$ and residual inhibitor activity towards $\mathrm{C} 1 \mathrm{~s}$ was subsequently assayed. The results ( Table $\mathrm{I} B$ ) clearly indicated that for several variants, the rate of proteolytic inactivation by HNE was changed as a consequence of the mutations. Substitutions at only P3 resulted in a two- to fourfold increase in $\mathrm{HNE}$ resistance at most, while $\mathrm{rCl}$ inh-3L seemed to be even more susceptible than wild type. However, the proteolytic inactivation of two double mutants, $\mathrm{rCl}$ inh5L3L and -5L3A, appeared to be decreased $\sim 10$-fold. This was found for purified $\mathrm{HNE}$, as well as for the supernatant of activated neutrophils. To confirm the data obtained with solid phase proteases, selected variants were purified from transfection media and further analyzed by SDS-PAGE, kinetic analyses, and in the presence of stimulated neutrophils. $\mathrm{rCl}$ inh-
5L3A and $-5 \mathrm{~L} 3 \mathrm{~L}$, which both displayed relatively unaffected binding to $\mathrm{C} 1 \mathrm{~s}$ and the highest $\mathrm{HNE}$ resistance, were characterized further in comparison with $\mathrm{rCl}$ inh-wt and -5V3A. The latter, studied as a control, contains substitutions at P5 and P3, but appeared as sensitive as wild type to proteolytic inactivation by HNE.

Fig. 1 demonstrates the ability of $\mathrm{rCl}$ inh-5L3A and $-5 \mathrm{~V} 3 \mathrm{~A}$ to form SDS-stable complexes with $\beta$-Factor XIIa, kallikrein, and plasmin. Plasmin was included in these experiments because inhibition of plasmin by $\mathrm{C} 1$ inhibitor has been demonstrated in vitro (28). Incubation with plasmin yielded complexes of $\sim 160 \mathrm{kD}$ and degradation products of 97 and $86 \mathrm{kD}$ (lanes 4,7 , and 10 ), the latter two most likely resulting from cleavage at the reactive site and/or at the $\mathrm{NH}_{2}$ terminus of $\mathrm{Cl}$ inhibitor, as has been described (28). There was no increase in cleavage of the variants by plasmin. The other results shown in Fig. 1 agree well with those of the RIAs presented in Table I; complex formation with $\beta$-Factor XIIa appeared unaffected

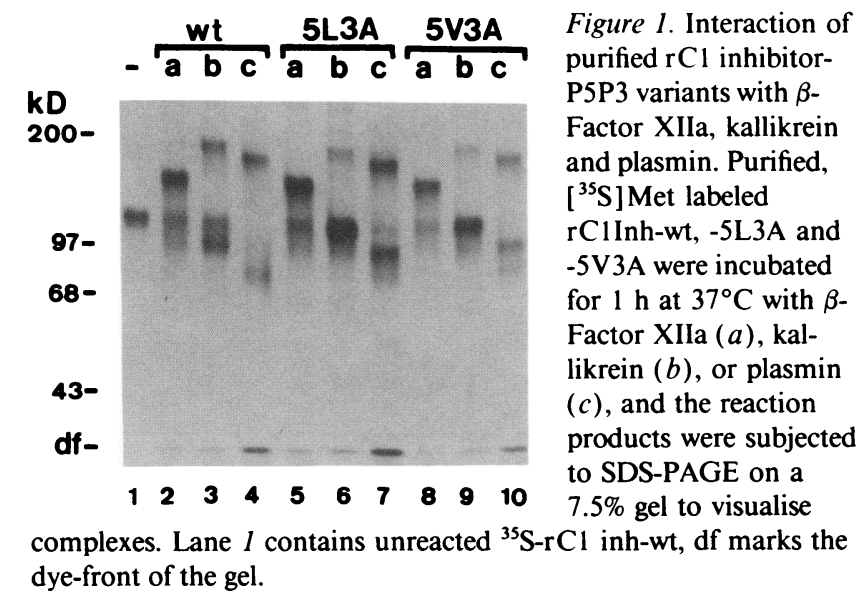



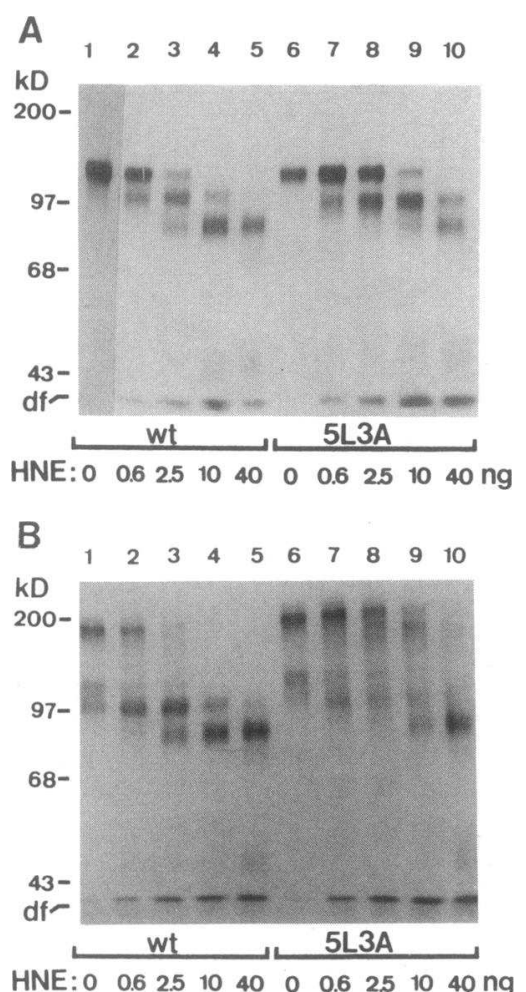

Figure 2. Purified $\mathrm{rCl}$ inh-5L3A displays resistance to catalytic inactivation by $\mathrm{HNE}$ and retains capability to form a complex with $\mathrm{C} 1 \mathrm{~s}$. Purified ${ }^{35} \mathrm{~S}-\mathrm{rCl}$ inh-wt and $-5 \mathrm{~L} 3 \mathrm{~A}$ were incubated with HNE (final concentration $0.6-40$ $\mathrm{nM}$ ) for $2 \mathrm{~h}$ at $37^{\circ} \mathrm{C}$ in $200 \mathrm{mM} \mathrm{NaCl}, 50 \mathrm{mM}$ Tris- $\mathrm{HCl}, \mathrm{pH} 8$. HNE was then inhibited by addition of $100 \mathrm{ng}$ eglin C. The reaction mixture was split in two samples and was either directly electrophoresed $(A)$ or after incubation with $200 \mathrm{ng} \mathrm{Cls}$ for $1 \mathrm{~h}$ at $37^{\circ} \mathrm{C}(B)$.

(lanes 2, 5, and 8 ), while interaction of the variants with kallikrein was decreased somewhat compared to wild type, as illustrated by the majority of $\mathrm{rCl}$ inh-P5/P3 variant molecules remaining in the native 104-kD form (lanes 6 and 9). Again, no increase in inhibitor cleavage was observed.

In Fig. 2, the resistance of $\mathrm{rC} 1$ inh-5 $\mathrm{L} 3 \mathrm{~A}$ against proteolytic inactivation by $\mathrm{HNE}$ is directly visualised. Although the degradation pattern characteristic of HNE (3) was also observed with $\mathrm{rCl}$ inh-5L3A (Fig. $2 A$ ), much higher HNE concentrations were required. The $\mathrm{NH}_{2}$ - and $\mathrm{COOH}$-terminal fragments cleaved off by HNE (3) are visible in the dye-front of the gel. Fig. $2 B$ shows the same incubation as in $A$, but with subsequent addition of $\mathrm{Cls}$ to analyze which fragments still bound
C1s. It can be seen that both $\mathrm{rCl}$ inh-wt and -5L3A formed complexes with $\mathrm{Cls}$ of $180 \mathrm{kD}$, and that after partial $\mathrm{NH}_{2}$-terminal cleavage by $\mathrm{HNE}, \mathrm{rCl}$ inh-5L3A formed a complex of about $170 \mathrm{kD}$ (Fig. $2 B$, lane 9 ). Densitometric scanning of the gel shown in Fig. $2 B$ established that the relative total amount of complexes in lane 10 ( $40 \mathrm{ng} \mathrm{HNE}$ ) was equal to that in lane 3 ( $2.5 \mathrm{ng}$ HNE; see Table II). This indicates that the difference in $\mathrm{HNE}$ resistance between $\mathrm{rCl}$ inhibitor wild type and 5L3A is 16-fold, in agreement with the experiments presented in Table I. In addition, Table II contains the result of scans of identical experiments as shown in Fig. 2 with 5V3A, and a more recently obtained $5 \mathrm{~A} 3 \mathrm{~A} \mathrm{C1}$ inhibitor variant, which also displayed HNE resistance. The results obtained with these two latter variants looked very similar to those in Fig. 2, $A$ and $B$. As the results of densitometric scans in Table II show, $\mathrm{rCl}$ inh$5 \mathrm{~V} 3 \mathrm{~A}$ behaved almost identically to wild type, and $\mathrm{rCl}$ inh$5 \mathrm{~A} 3 \mathrm{~A}$ behaved like $5 \mathrm{~L} 3 \mathrm{~A}$, with the difference that $5 \mathrm{~A} 3 \mathrm{~A}$ appeared slightly less resistant to inactivation by $\mathrm{HNE}$, and generated a somewhat more cleaved 94-kD Cl inhibitor upon incubation with $\mathrm{Cls}$ alone. These experiments show that $\mathrm{rCl}$ inh-5L3A and $-5 \mathrm{~A} 3 \mathrm{~A}$ resisted inactivation and remained functional for a prolonged period in the presence of HNE. Additional experiments (not shown) established that the smallest fragment of $\mathrm{C} 1$ inhibitor capable of complex formation is $\sim 50$ $\mathrm{kD}$, representing the serpin domain with the $\mathrm{NH}_{2}$-terminal part containing most of the carbohydrate sidechains (13) cleaved off.

It has been reported that cleavage of $\mathrm{C} 1$ inhibitor proceeds faster in the presence of intact, stimulated neutrophils in comparison with only the supernatant of activated cells (3). In addition, much attention has been given recently to the serpincleaving activity of metalloproteases, exerted in combination with reactive oxygen species released from triggered neutrophils $(29,30)$. Neutrophil collagenase was shown to cleave several serpins, notably $\alpha 1$-antitrypsin and $\mathrm{Cl}$ inhibitor, the latter being cleaved between P6 and P5 (31). Therefore, we performed experiments to investigate the relative importance of serineproteases, metalloproteases, and the oxidative burst in cleavage of $\mathrm{Cl}$ inhibitor. Second, we tested whether the P5/P3 variants that resisted cleavage by purified $\mathrm{HNE}$ and the super-

Table II. Densitometric Scan of SDS-gels of rC1 inh Variants Incubated with HNE and Subsequently with C1s

\begin{tabular}{|c|c|c|c|c|c|c|c|c|c|c|}
\hline $\mathrm{rCl}$ Inhibitor & & & Wild typ & & & & & $5 \mathrm{~L} 3 \mathrm{~A}$ & & \\
\hline \multicolumn{11}{|l|}{$A$} \\
\hline ng HNE & 0 & 0.6 & 2.5 & 10 & 40 & 0 & 0.6 & 2.5 & 10 & 40 \\
\hline Complex > $104 \mathrm{kD}$ & 51 & 39 & 15 & & & 57 & 60 & 60 & 47 & 15 \\
\hline Native $104 \mathrm{kD}$ & 19 & & & & & $35^{*}$ & 10 & 8 & 5 & \\
\hline Cleaved $<104 \mathrm{kD}$ & 23 & 57 & 84 & 100 & 100 & $35^{*}$ & 29 & 28 & 43 & 84 \\
\hline$B$ & & & $5 \mathrm{~V} 3 \mathrm{~A}$ & & & & & $5 \mathrm{~A} 3 \mathrm{~A}$ & & \\
\hline ng HNE & 0 & 0.6 & 2.5 & 10 & 40 & 0 & 0.6 & 2.5 & 10 & 40 \\
\hline Complex > $104 \mathrm{kD}$ & 57 & 45 & 9 & 2 & & 41 & 42 & 41 & 33 & 5 \\
\hline Native $104 \mathrm{kD}$ & 28 & 9 & 11 & & & 25 & 11 & 10 & 2 & \\
\hline Cleaved $<104 \mathrm{kD}$ & 15 & 46 & 80 & 98 & 100 & 33 & 47 & 49 & 65 & 95 \\
\hline
\end{tabular}

(A) Densitometric scan of Fig. $2 \mathrm{~B}$. Numbers given represent relative intensities of $\mathrm{C} 1$ inhibitor bands, in percentage of total, as determined by integration. All peaks corresponding to bands with a apparent mobility $>104 \mathrm{kD}$ were grouped as complexes, and those $<94 \mathrm{kD}$, with the exception of the postcomplex peptide in the dye-front of the gel, as cleaved inhibitor fragments. $(B)$ Results of a gelscan of an identical experiment with $\mathrm{rCl}$ inh-5V3A and $-5 \mathrm{~A} 3 \mathrm{~A}$. * No resolution of these two peaks under the conditions of the scan. 
natant of activated neutrophils would retain this capacity in the presence of intact, stimulated cells. In Fig. $3 \mathrm{~A}$, the decrease in $\mathrm{Cl}$ inhibitor activity upon stimulation of neutrophils by either PMA or FMLP is shown. It appeared that the decline in inhibitor activity, determined by titration against $\mathrm{C} 1 \mathrm{~s}$ in a subsequent incubation, proceeded significantly faster after stimulation with FMLP than with PMA. The former is known (especially in the presence of cytochalasin B) to generate a fast degranulation concurrently with the oxidative burst (32), and the latter yields a fast burst and a relatively slow degranulation (33). Next, neutrophils were stimulated in the presence of various inhibitors. Eglin $\mathrm{C}$ inhibits the serine proteases $\mathrm{HNE}$, proteinase 3 , and cathepsin $\mathrm{G}(34,35), 1,10$-phenanthroline is an inhibitor of metalloproteases, and diphenyleneiodonium (DPI) was used as a specific inhibitor of the NADPH oxidase (36). The results, shown in Fig. $3 \mathrm{~B}$, clearly indicated that eglin $\mathrm{C}$ alone was sufficient to eliminate inactivation of $\mathrm{C} 1$ inhibitor by stimulated neutrophils. DPI, a strong inhibitor of the oxidative burst (reference 36 , and results not shown) at the concentration used ( $5 \mu \mathrm{M})$, had no effect. The delay in $\mathrm{Cl}$ inhibitor inactivation caused by 1,10 -phenanthroline seemed to indicate a partial involvement of metalloproteases. However, additional experiments showed that 1,10-phenanthroline in fact had a negative effect on the degranulation response, as measured by the appearance of the azurophilic granule membrane

A

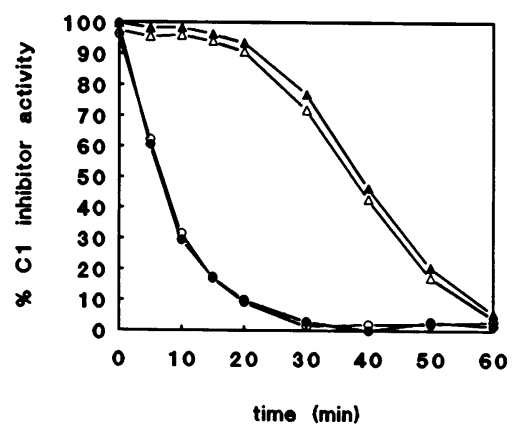

B

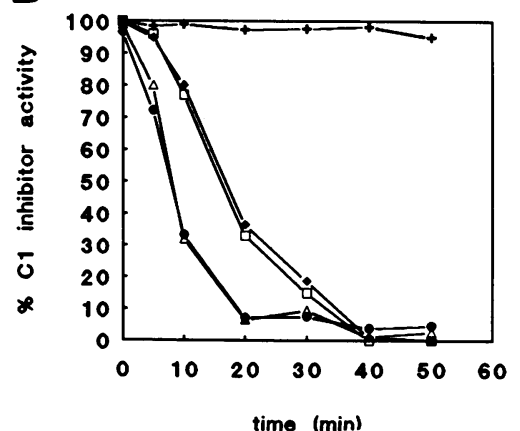

Figure 3. Inactivation of $\mathrm{Cl}$ inhibitor by stimulated neutrophils; effect of the stimulus $(A)$ and specific inhibitors $(B)$. (A) Plasma $\mathrm{Cl}$ inhibitor ( $5 \mu \mathrm{g}$ in a final volume of $1 \mathrm{ml}$ ) was incubated in the presence of purified human neutrophils $\left(2 \times 10^{6} / \mathrm{ml}\right)$. At time 0 , cells were stimulated with FMLP ( $1 \mu \mathrm{M}$; circles) or PMA (100 ng/ $\mathrm{ml}$; triangles $)$. Duplicate samples were removed at the indicated times, and proteolytic activity released from the cells was quickly quenched in a mixture of eglin C, EDTA and 1,10-phenanthroline. Methionine was present as $\mathrm{HOCl}$ scavenger. $\mathrm{Re}-$ sidual $\mathrm{Cl}$ inhibitor was subsequently determined against $\mathrm{Cls}$ in a chromogenic assay. Results are expressed as percentage activity relative to zero time. $-0-$ and $-\bullet-$, fMLP; $-\triangle-$ and $-\triangle-$, PMA. ( $B$ ) Conditions were as under A. Cells were stimulated with FMLP in the presence of specific inhibitors, as indicated; $10 \mu \mathrm{M}$ eglin C, $2 \mathrm{mM} 1,10$-phenanthroline, $5 \mu \mathrm{M}$ DPI, or a combination of 1,10phenanthroline and DPI. Stimulating the cells in the presence of all these inhibitors gave the same results as with eglin $\mathrm{C}$ alone (not shown). $-\bullet-$, None; -+- , eglin; $-\square-$, phenanthroline; $-\triangle-$, DPI; $-\downarrow$, , phenanthroline and DPI.

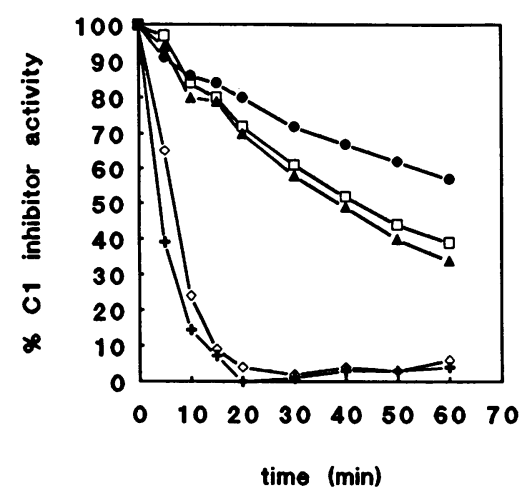

Figure 4. Proteolytic inactivation of $\mathrm{rCl}$ inhibitor $\mathrm{P} 5 / \mathrm{P} 3$ variants by activated neutrophils. Purified plasma $\mathrm{Cl}$ inhibitor or various $\mathrm{rCl}$ inh-P5/P3 variants (final concentration 5 $\mu \mathrm{g} / \mathrm{ml}$ ) were incubated with neutrophils. At time 0 , cells were stimulated with FMLP.

Conditions and calculation of results was as described in Methods

and the legend to Fig. $3 .-+-$, Wild type; $-\bullet-, 5 \mathrm{~L} 3 \mathrm{~A} ;-\square-$, $5 \mathrm{~A} 3 \mathrm{~A} ;-\wedge-, 5 \mathrm{~L} 3 \mathrm{~L} ;-\diamond-$, plasma $\mathrm{Cl}$ inhibitor.

marker CD63 (33) on the outer cell membrane (Niessen, H. W. M., and E. Eldering, unpublished observation).

When purified recombinant $\mathrm{C} 1$ inhibitor $\mathrm{P} 5 / \mathrm{P} 3$ variants were incubated in the presence of FMLP-stimulated neutrophils, a pronounced delay in proteolytic inactiv ation was found in comparison with plasma derived and recombinant normal $\mathrm{Cl}$ inhibitor (Fig. 4). $20 \mathrm{~min}$ after FMLP stimulation, functional activity of wild type recombinant and plasma $\mathrm{Cl}$ inhibitor was $<5 \%$, while the $\mathrm{P} 5 / \mathrm{P} 3$ variants still displayed $70-80 \%$ activity. The half-time of $\mathrm{Cl}$ inhibitor inactivation $\left(t_{1 / 2}\right)$ in comparison with $\mathrm{rCl}$ inh-wt was increased $\sim 18$-fold for $\mathrm{rCl}$ inh-5L3A, and eightfold for $\mathrm{rC} 1$ inh-5L3L and $-5 \mathrm{~A} 3 \mathrm{~A}$, in good agreement with the previous results. A rough estimate of the $k_{\text {cat }} / K_{\mathrm{m}}$ value, where $k_{\text {cat }}$ is the maximal catabolic rate, as defined by $\ln 2 /[\mathrm{E}] \times t_{1 / 2}(37)$, where [E] is the enzyme concentration, for $\mathrm{Cl}$ inhibitor as substrate for $\mathrm{HNE}$ yielded $\sim 400$ $\mathrm{M}^{-1} \mathrm{~s}^{-1}$ under the conditions used in these experiments. This is well above the threshold proposed by Mast et al. (37) for the reaction to be of physiological significance. Together, these experiments demonstrate that proteolytic inactivation of $\mathrm{C} 1 \mathrm{in}$ hibitor by activated neutrophils is caused predominantly by serine proteases released from azurophilic granules and that substitutions at both HNE cleavage sites can significantly reduce the rate of inactivation.

A detailed evaluation with respect to complex stability and kinetic constants of all $12 \mathrm{rCl}$ inhibitor P5/P3 variants with the various target proteases is beyond the scope of the present article and will be reported elsewhere (Eldering, E., C. C. M. Huijbregts, Y. T. P. Lubbers, C. Longstaff, J. H. Nuijens, and C. E. Hack, manuscript submitted for publication). In agreement with the results presented here, kinetic analysis under pseudo-first order conditions generated association rate constants with $\mathrm{C} 1 \mathrm{~s}$ of purified $\mathrm{rCl}$ inh-P5/ $\mathrm{P} 3$ variants that varied between $1.3 \times 10^{4} \mathrm{M}^{-1} \mathrm{~s}^{-1}$ for $\mathrm{rCl}$ inh-3R and $4.2 \times 10^{4}$ $\mathrm{M}^{-1} \mathrm{~s}^{-1}$ for wild type. Fig. 5 shows a representative example of an inhibition experiment with $\mathrm{C} 1 \mathrm{~s}$ and purified $\mathrm{rCl}$ inh-wt. The inset shows the linear relationship between I and the apparent rate constant $k_{\text {obs }}$ for $\mathrm{rCl}$ inh-wt and 5L3A. As described (21), the overall inhibition mechanism conformed to a onestep reversible reaction. The observed $k_{\text {off }}$ value of wild type $\mathrm{Cl}$ inhibitor is too low, however $\left(1-2 \times 10^{-6} \mathrm{~s}^{-1}\right)$ to be physiologically relevant (21) and no significant changes were found for the P5/P3 variants (Eldering, E., C. C. M. Huijbregts, Y. T. P. Lubbers, C. Longstaff, J. H. Nuijens, and C. E. Hack, manuscript submitted for publication). 


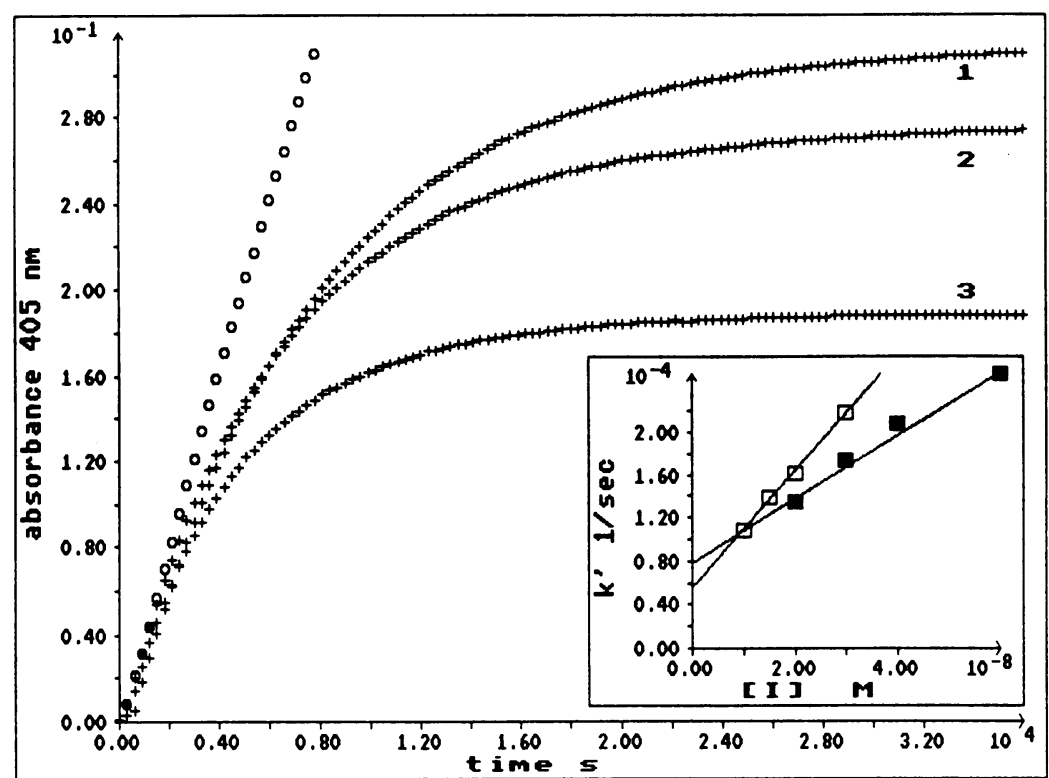

Figure 5. Progress curves for inhibition of C1s by recombinant $\mathrm{Cl}$ inhibitor wild type. $\mathrm{Cls}$ ( final concentration $0.4 \mathrm{nM}$ ) was added to a solution containing chromogenic substrate S-2314 and purified $\mathrm{rCl}$ inhwt. Changes in absorbance at $405 \mathrm{~nm}$ were recorded with a spectrophotometer (Lambda 2; Perkin Elmer Corp., Norwalk, CT) equipped with a six-cell transporter for $10 \mathrm{~h}$ and analyzed as described in Methods. Shown are the data for $\mathrm{Cls}$ alone (0), and the datapoints for $15 \mathrm{nM}(1), 20 \mathrm{nM}(2)$, and $30 \mathrm{nM}$ (3) rCl inh-wt. The inset shows a plot of $k_{\text {obs }}\left(k^{\prime}\right)$ vs. [I] for $\mathrm{rCl}$ inh-wt (open squares) and for $\mathrm{rC1}$ inh-5L3A (closed squares), obtained from a similar experiment.
The association rate of purified $\mathrm{Cl}$ inhibitor with $\mathrm{Cls}$, which is relatively low compared to other serpin-protease interactions (1), appears to be augmented upon addition of heparin $(38,39)$, or when measured with $\mathrm{Cls}$ incorporated in the complete $\mathrm{Cl}$ complex (40). The reaction rate of the $\mathrm{P} 5$ / $\mathrm{P} 3$ variants was stimulated in the presence of heparin to a similar extent as that of plasma and recombinant $\mathrm{Cl}$ inhibitor wild type, as demonstrated in Fig. 6 for $\mathrm{rCl}$ inh-5L3A. Comparable sets of inhibition progress curves were obtained for $\mathrm{rCl}$ inh-wt, $-5 \mathrm{~L} 3 \mathrm{~A},-5 \mathrm{~L} 3 \mathrm{~L}$ and $-5 \mathrm{~V} 3 \mathrm{~A}$. The increase in $k_{\text {on }}$ for $\mathrm{C} 1 \mathrm{~s}$ in the presence of $10 \mathrm{U} / \mathrm{ml}$ heparin was similar, generating an average stimulation factor of $8.4 \pm 0.6$. These results indicated that the structural determinants that mediate the interaction with heparin are unperturbed in the $\mathrm{P} 5 / \mathrm{P} 3$ variants.

Association rates with $\beta$-Factor XIIa were obtained as described $(21,27)$, using final concentrations of $20 \mathrm{nM} \beta$-Factor
XIIa and 200-600 $\mathrm{nM} \mathrm{rCl}$ inhibitor variants. The association rate constant of $\mathrm{rCl}$ inh-wt with $\beta$-Factor XIIa was determined to be $3.9 \times 10^{3} \mathrm{M}^{-1} \mathrm{~s}^{-1}$, and similar values were derived for most variants. Kinetic experiments with kallikrein and various P5/P3 variants were performed as described (17, 41), using final concentrations of $20 \mathrm{nM}$ kallikrein and $200-400 \mathrm{nM} \mathrm{rCl}$ inhibitor. The association rate constant of $\mathrm{rCl}$ inh-wt and 5L3L with kallikrein was calculated to be $1.6 \times 10^{4} \mathrm{M}^{-1} \mathrm{~s}^{-1}$. Approximately a fivefold reduction in $k_{\text {on }}$ was found for $5 \mathrm{~L} 3 \mathrm{~A}$ and $5 \mathrm{~A} 3 \mathrm{~A}$, and $5 \mathrm{~V} 3 \mathrm{~A}$ appeared to react almost ninefold slower than wild type. Table III summarizes the results of the kinetic studies for $\mathrm{rCl}$ inh-wt, the HNE-resistant 5L3A, 5L3L, and $5 \mathrm{~A} 3 \mathrm{~A}$ variants, and the $5 \mathrm{~V} 3 \mathrm{~A}$ variant. The values of the rate constants obtained for $\mathrm{rCl}$ inh-wt with $\mathrm{C} 1 \mathrm{~s}, \beta$-Factor XIIa and kallikrein corresponded well with those published for purified plasma $\mathrm{Cl}$ inhibitor $(17,27,38,41)$.

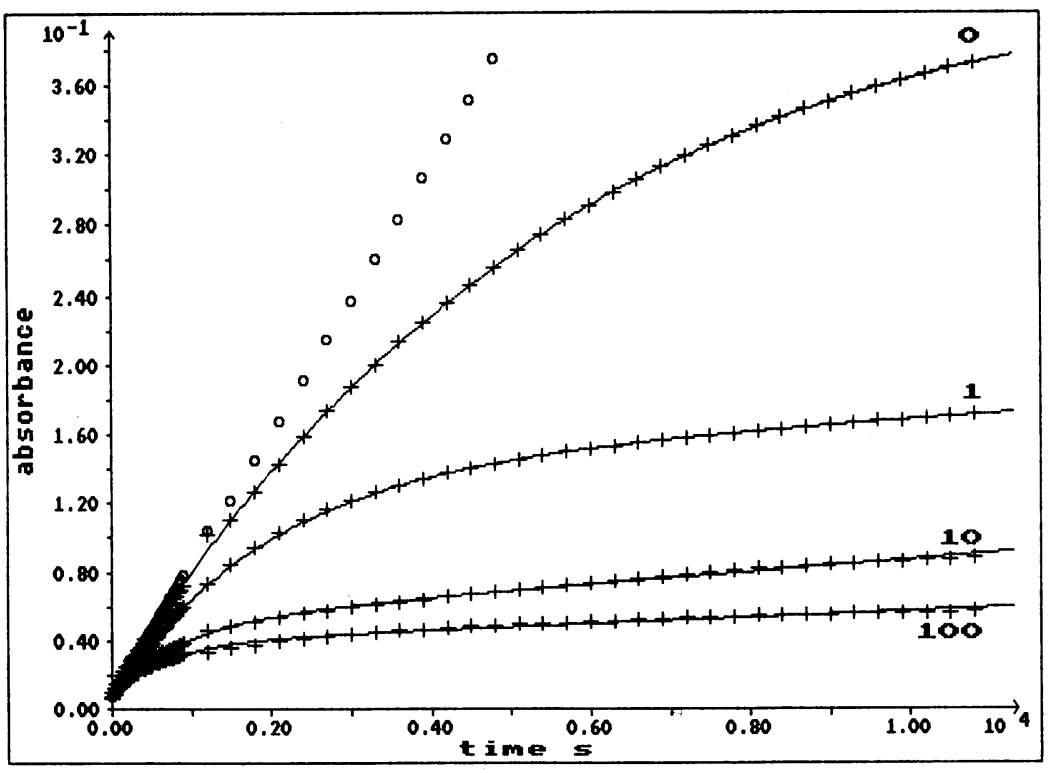

Figure 6. Inhibition of $\mathrm{C} 1 \mathrm{~s}$ by $\mathrm{rC} 1$ inhibitor $5 \mathrm{~L} 3 \mathrm{~A}$ in the presence of heparin. Conditions were as described in Methods and the legend to Fig. 3, employing final concentrations of $2 \mathrm{nM} \mathrm{C1s}$ and $25 \mathrm{nM} \mathrm{rCl}$ inh5L3A. Shown are the datapoints for $\mathrm{Cls}$ alone $(\mathrm{O})$, and the datapoints $(+)$ as well as the calculated curves upon fitting to the integrated rate equation for slow binding inhibition for the various concentrations of heparin. Final heparin concentrations are indicated for each curve in $\mathrm{U} / \mathrm{ml}$. Comparable sets of curves were obtained for $\mathrm{rCl}$ inh-wt, $-5 \mathrm{~L} 3 \mathrm{~L}$, and $-5 \mathrm{~V} 3 \mathrm{~A}$. 
Table III. Association Rate Constants

of Recombinant C1 Inhibitor P5/P3 Variants

\begin{tabular}{lccc}
\hline $\begin{array}{l}\text { rCl Inhibitor } \\
\text { species }\end{array}$ & Cls $k_{\text {on }}$ & Kallikrein $k_{\text {on }}$ & $\begin{array}{c}\beta \text {-Factor } \\
\text { XIIa } k_{\text {on }}\end{array}$ \\
\hline & $10^{4} M^{-1} s^{-1}$ & $10^{3} M^{-1} s^{-1}$ & $10^{3} M^{-1} s^{-1}$ \\
Wild type & $4.2 \pm 0.5$ & $15.8 \pm 1.3$ & $3.9 \pm 0.3$ \\
5L3A & $2.6 \pm 0.6$ & $2.8 \pm 0.1$ & $3.7 \pm 0.3$ \\
5L3L & $4.7 \pm 0.9$ & $15.7 \pm 0.5$ & $2.6 \pm 0.1$ \\
5V3A & $2.9 \pm 0.3$ & $1.8 \pm 0.1$ & $4.2 \pm 0.2$ \\
5A3A & ND & $3.1 \pm 0.1$ & ND \\
& & & \\
\hline
\end{tabular}

$k_{\text {on }}$ for Cls, kallikrein, and $\beta$-Factor XIla were obtained as described in Methods. Calculated constants are the mean $\pm \mathrm{SE}$ of at least three separate experiments. ND, not done

\section{Discussion}

Several studies have demonstrated the therapeutic potential of recombinant serpins derived from $\alpha 1$-antitrypsin in inflammatory conditions $(9,10)$. However, these and other $(11,42)$ reports have also attenuated earlier expectations $(43,44)$ that the specificity of serpins could be predictably modified by alterations in the reactive site loop, based on the known substrate specificity of target proteases and on comparisons of serpin loop sequences. It is now generally agreed that residues outside the reactive site loop are also critical in defining specificity; e.g., as has been demonstrated recently for plasminogen activator inhibitor-1 (45). Furthermore, it is becoming increasingly clear that the reactive site loop of serpins is a highly specialized structure $(46,47)$ that probably cannot be directly compared to small substrates. The results presented here demonstrate the feasibility of an alternative strategy that maintains the inherent specificity of serpins to construct variants that are resistant to catalytic inactivation by nontarget proteases. Conservative substitutions at both HNE cleavage sites in the reactive centre loop of $\mathrm{Cl}$ inhibitor can apparently reduce the proteolytic inactivation by $\mathrm{HNE}$ about 16 -fold, while the specific interaction with various target proteases seems moderately affected. Since our efforts were aimed at obtaining HNE resistance, as well as at preserving inhibitory function, the amino acid changes were predominantly semiconservative. Of 12 variants constructed, $\mathrm{rC1}$ inh-5L3A, -5L3L and -5A3A displayed significant resistance to purified $\mathrm{HNE}$, as well as to stimulated neutrophils. Complete HNE resistance was not obtained with the substitutions used, which is perhaps not surprising considering the general preference of $\mathrm{HNE}$ for $\mathrm{Pl}$ residues with a medium-sized aliphatic side chain (48). There was a good correlation, however, between the order of $P 1$ residues preferred by HNE in small peptide substrates and chloromethylketone inhibitors $($ Ile $=$ Val $>$ Leu $>$ Ala $)(48-51)$, and the substitutions conferring $\mathrm{HNE}$ resistance in $\mathrm{Cl}$ inhibitor (Leu or Ala for Ile or $\mathrm{Val}$ ). In addition, our results were also in agreement with computer modeling that has predicted that P1-Ile would be a better substrate for HNE than P1-Leu (48).

Functional capacity of the variants could be demonstrated by the formation of stable complexes with $\mathrm{Cls}, \beta$-Factor XIIa, kallikrein and plasmin, both with radioimmunoassays and on SDS gels. Kinetic analyses indicated that the association rate constant with $\mathrm{Cls}$ for the HNE-resistant variants is reduced twofold at most, and seems unaffected with $\beta$-Factor XIIa. The effect of the substitutions on the association rate constant with kallikrein ranged from a quite significant ninefold reduction in the case of $5 \mathrm{~V} 3 \mathrm{~A}$ to an unchanged association rate for $5 \mathrm{~L} 3 \mathrm{~L}$. It appears that especially the $\mathrm{P} 3$ amino acid is more critical in the interaction with kallikrein compared with $\beta$-Factor XIIa and $\mathrm{C} 1$ s. Collectively, the results from kinetic analyses showed that $\mathrm{rCl}$ inh-5L3L has unperturbed functional characteristics, while the various inactivation experiments demonstrated that 5L3A has the highest resistance to HNE-mediated cleavage. The RIAs using solid-phase proteases provided a quick and sensitive screen to detect (residual) binding capacity. Some discrepancies between the RIAs and kinetic experiments were observed; e.g., we found that in the $\beta$-Factor XIIa RIA, 5L3A binds for $\sim 46 \%$ compared to wild type, but kinetic analysis indicated similar association rate constants. These differences may result from the fact that Sepharose-coupled proteases appear to react slower with $\mathrm{Cl}$ inhibitor, and also with chromogenic substrates (unpublished observations). In our experience, only the absence of binding, or a drastic reduction, in the RIAs indicates a complete or significant loss of function (i.e., leading to a $>10$-fold reduction in $k_{\text {on }}$, see also reference 21 ). An important observation with these HNE-resistant variants was that the amino acid changes did not result in significantly increased inhibitor turnover by target proteases. This was evident from SDS-PAGE analysis (Figs. 1 and $2 \mathrm{~B}$, Table II), and also from studies that monitored the possible appearance of cleaved $\mathrm{rCl}$ inhibitor upon interaction with target proteases under nondenaturing conditions (Eldering, E., C. C. M. Huijbregts, Y. T. P. Lubbers, C. Longstaff, J. H. Nuijens, and C. E. Hack, manuscript submitted for publication). In contrast, certain recombinant serpins derived from $\alpha 1$-antitrypsin have been shown to be cleaved considerably by plasmin in vitro (12), and are reported to circulate in the cleaved form in septic shock (52).

Since maximally only two residues in the reactive centre loop were exchanged, perturbations of the overall $\mathrm{Cl}$ inhibitor tertiary structure can be presumed to be nonexistent or minimal in the variants described here. This may be advantagous in a physiological setting, where it can be expected that any specific interaction with potential third components is maintained. Although $\mathrm{Cl}$ inhibitor is not generally viewed as a heparin-dependent serpin, it is known that its activity against $\mathrm{C} 1 \mathrm{~s}$ is stimulated in the presence of this glycosaminoglycan $(38,39)$. Inhibition experiments in the presence of heparin indeed demonstrated that the activity of the P5/P3 variants is stimulated identical to wild type $\mathrm{Cl}$ inhibitor, indicating that the substitutions did not interfere with the determinants that mediate this specific interaction.

Apart from the well-established capacity of HNE to catalytically cleave serpins such as antithrombin III, $\alpha 2$-antiplasmin, and $\mathrm{Cl}$ inhibitor (2-4), various articles in recent years have described that metalloproteases, in combination with reactive oxygen species, can also cleave serpins, in particular $\alpha 1$-antitrypsin, near the reactive center $(29,30)$. This "serpinase" (53) activity of metalloproteases is, however, relatively low (i.e., 24-h incubations are needed to generate significant serpin cleavage in most reports), and is measured in the supernatant of activated neutrophils after addition of the serine protease inhibitor PMSF. Mast et al. (37) have performed a detailed 
evaluation of the kinetics of serpin inactivation by matrix metalloproteases, and they concluded that these reactions generally proceeded too slow to be of physiological significance. Experiments presented here established that the $\mathrm{HNE}$ inhibitor eglin $\mathrm{C}$ is sufficient to eliminate inactivation of $\mathrm{Cl}$ inhibitor by stimulated neutrophils. The $\mathrm{C} 1$ inhibitor $\mathrm{P} 5 / \mathrm{P} 3$ variants that displayed resistance against purified $\mathrm{HNE}$ retained this capability in the presence of activated, intact cells, and the difference with $\mathrm{Cl}$ inhibitor wild type was of the same magnitude under both conditions. The results strongly point to HNE (and perhaps the closely related proteinase 3 [35]) as the most predominant cause of $\mathrm{Cl}$ inhibitor cleavage by neutrophils. We found no evidence for an involvement of the oxidative burst in $\mathrm{Cl}$ inhibitor inactivation. Unlike $\alpha 1$-antitrypsin, $\mathrm{Cl}$ inhibitor does not contain oxidation-sensitive methionine residues in the reactive center loop. Pemberton et al. (3) presumed that short-lived reactive oxygen species might be responsible for the observed increase in cleavage of $\mathrm{Cl}$ inhibitor when comparing intact, stimulated neutrophils with only the supernatant of cells. Alternatively, this difference can perhaps be explained by the reported capacity of $\mathrm{Cl}$ inhibitor to adhere to neutrophils (54), which would cause an underestimation of the remaining $\mathrm{Cl}$ inhibitor in the supernatant after the cells are spun down. In addition, the general, damaging effect of reactive oxygen species may be quenched in plasma by the presence of a vast excess of other proteins, a situation imitated in our experimental system by the presence of $0.5 \%$ BSA. Based on the above considerations, and assuming that they have the same kinetic capabilities as matrix metalloproteases, we doubt whether neutrophil metalloproteases, although they are certainly capable of proteolytic inactivation of $\mathrm{Cl}$ inhibitor, do so at a significant rate compared to HNE, which is simultaneously released by activated neutrophils.

We are aware that although HNE is clearly capable of inactivating $\mathrm{Cl}$ inhibitor and other serpins in vitro, it remains to be established that this indeed occurs in vivo under conditions of systemic inflammation. This important validation of the in vitro data could perhaps be accomplished by purification of $\mathrm{Cl}$ inhibitor from the plasma of septic shock patients where a considerable level of cleavage is sometimes found (19), followed by $\mathrm{NH}_{2}$-terminal sequencing to determine the site $(\mathrm{s})$ of cleavage. The availability of $\mathrm{HNE}$ resistant variants of $\mathrm{Cl}$ inhibitor provides novel possibilities to investigate the exact contribution of excessive HNE activity to the deregulation of the complement and contact activation systems in inflammatory conditions. It can be assumed that this approach is also applicable to other serpins. Further testing in experimental models of inflammatory disease is needed to determine the potential usefulness of such variants as a therapeutic agent.

\section{Acknowledgments}

Recombinant $\mathrm{Cl}$ inhibitor variants were skilfully purified by Yvonne Lubbers. We greatly appreciate the encouragement and assistance of Dr. Colin Longstaff (NBSB, UK) with the kinetic analyses. We would like to thank Hans Niessen from the Dept. of Blood Cell Chemistry for purification of neutrophils and degranulation experiments.

This work was supported by a grant from the Dutch Organization for Scientific Research (NWO). A. J. Verhoeven is a research fellow at the Royal Dutch Acadamy of Sciences.

\section{References}

1. Travis, J., and G. S. Salvesen. 1983. Human plasma proteinase inhibitors. Annu. Rev. Biochem. 52:655-709.

2. Brower, M. S., and P. C. Harpel. 1982. Proteolytic cleavage and inactivation of $\alpha 2$-plasmin inhibitor and $\mathrm{Cl}$ Inactivator by human polymorphonuclear leukocyte elastase. J. Biol. Chem. 257:9849-9854.

3. Pemberton, P. A., R. A. Harrison, P. J. Lachmann, and R. W. Carrell. 1989. Structural basis for neutrophil inactivation of C1 Inhibitor. Biochem. J. 258:193198.

4. Jordan, R. E., J. Kilpatrick, and R. M. Nelson. 1987. Heparin promotes the inactivation of antithrombin by neutrophil elastaes. Science (Wash. DC). 237:777-779.

5. Carrell, R. W., and M. C. Owen. 1985. Plakalbumin, $\alpha 1$-antitrypsin, antithrombin and the mechanism of inflammatory thrombosis. Nature (Lond.). 317:730-732.

6. Weiss, S. J. 1989. Tissue destruction by neutrophils. N. Engl. J. Med. 320:365-376.

7. Vissers, M. C. M., P. M. George, I. C. Bathurst, S. O. Brennan, and C. C. Winterbourn. 1988. Cleavage and inactivation of $\alpha 1$-antitrypsin by metalloproteinases released from human neutrophils. J. Clin. Invest. 82:706-711.

8. Desrochers, P. E., and S. J. Weiss. 1988. Proteolytic inactivation of alpha-1proteinase inhibitor by a neutrophil metalloproteinase. J. Clin. Invest. 81:16461650.

9. Schapira, M., M-A. Ramus, B. Weaber, H. R. Brunner, S. Jallat, D. Carvallo, C. Roitsch, and M. Courtney. 1987. Protection by recombinant $\alpha 1$-antitrypsin $\mathrm{Ala}^{357} \mathrm{Arg}^{358}$ against arterial hypotension induced by Factor XII fragment. J. Clin. Invest. 80:582-585.

10. Colman, R. W., D. N. Flores, R. A. de la Cadena, C. F. Scott, L. Cousens, P. J. Barr, I. B. Hoffman, F. Kueppers, D. Fisher, S. Idell, and J. Pisarello. 1988. Recombinant $\alpha 1$-antitrypsin Pittsburgh attenuates experimental gram-negative septicemia. Am. J. Pathol. 130:418-426.

11. George, P. M., P. A. Pemberton, I. C. Bathurst, R. W. Carrell, H. L. Gibson, S. Rosenberg, R. A. Hallewell, and P. J. Barr. 1989. Characterization of antithrombins produced by active site mutagenesis of human $\alpha 1$-antitrypsin expressed in yeast. Blood. 73:490-496.

12. Patston, P. A., N. Roodi, J. A. Schifferli, R. Bischoff, M. Courtney, and M. Schapira. 1990. Reactivity of $\alpha 1$-antitrypsin mutants against proteolytic enzymes of the kallikrein-kinin, complement and fibrinolytic systems. J. Biol. Chem. 265:10786-10791.

13. Perkins, S. J., K. F. Smith, S. Amatayakul, D. Ashford, T. W. Rademacher, R. A. Dwek, P. J. Lachmann, and R. A. Harrison. 1990. Two-domain structure of the native and reactive centre cleaved forms of $\mathrm{C} 1$ Inhibitor of human complement by neutron scattering. J. Mol. Biol. 214:751-763.

14. Donaldson, V. H., and R. R. Evans. 1963. A biochemical abnormality in hereditary angioneurotic edema. Am. J. Med. 35:37-44.

15. Davis, A. E. III. 1988. C1 Inhibitor and hereditary angioneurotic edema. Annu. Rev. Immunol. 6:595-628.

16. Sim, R. G., A. Reboul, G. J. Arlaud, C. L. Villiers, and M. G. Colomb. 1979. Interaction of ${ }^{125}$-I labeled complement components $\mathrm{Clr}$ and $\mathrm{Cls}$ with protease inhibitors in plasma. FEBS(Fed. Eur. Biochem. Soc.) Lett. 97:111-115.

17. Van der Graaf, F., J. A. Koedam, J. H. Griffin, and B. N. Bouma. 1983. Interaction of human plasma kallikrein and its light chain with $\mathrm{Cl}$ Inhibitor. Biochemistry. 22:4860-4866.

18. Pixley, R. A., M. Schapira, and R. W. Colman. 1985. The regulation of human factor XIla by plasma protease inhibitors. J. Biol. Chem. 260:1723-1729.

19. Nuijens, J. H., A. J. M. Eerenberg-Belmer, C. C. M. Huijbregts, W. O Schreuder, R. J. F. Felt-Bersma, J. J. Abbink, L. G. Thijs, and C. E. Hack. 1989. Proteolytic inactivation of plasma $\mathrm{Cl}$ inhibitor in sepsis. J. Clin. Invest. 84:443450.

20. Hack, C. E., J. H. Nuijens, R. J. F. Felt-Bersma, W. O. Schreuder, A. J. M. Eerenberg, J. Paardekooper, W. Bronsveld, and L. G. Thijs. 1989. Elevated plasma levels of the anaphylatoxin $\mathrm{C} 3 \mathrm{a}$ are associated with a fatal outcome in sepsis. Am. J. Med. 86:20-26.

21. Eldering, E., C. C. M. Huijbrechts, Y. T. P. Lubbers, C. Longstaff, J. H Nuijens, and C. E. Hack. 1992. Characterization of recombinant Cl inhibitor PI variants. J. Biol. Chem. 267:7013-7020.

22. Eldering, E., J. H. Nuijens, and C. E. Hack. 1988. Expression of functional human C1 Inhibitor in COS cells. J. Biol. Chem. 263:11776-11779.

23. Kramer, W., V. Drutsa, H-W. Jansen, B. Kramer, M. Pflugfelder, and H-J. Fritz. 1984. The gapped duplex DNA approach to oligonucleotide-directed mutation construction. Nucleic Acids Res. 12:9441-9455.

24. Pilatte, Y., C. H. Hammer, M. M. Frank, and L. F. Fries. 1989. A new simplified procedure for $\mathrm{Cl}$ inhibitor purification. J. Immunol. Methods. 120:37-43.

25. Verhoeven, A. J., M. L. J. van Schaik, D. Roos, and R. S. Weening. 1988. Detection of carriers of the autosomal form of chronic granulomatous disease. Blood. 2:505-507. 
26. Morrison, J. F., and C. T. Walsh. 1988. The behavior and significance of slow-binding enzyme inhibitors. Adv. Enzymol. Relat. Areas Mol. Biol. 61:201301.

27. de Agostini, A., H. R. Lijnen, R. A. Pixley, R. W. Colman, and M. Schapira. 1984. Inactivation of Factor XII active fragment in normal plasma. J. Clin. Invest. 73:1542-1549.

28. Harpel, P. C., and N. R. Cooper. 1975. Studies on human plasma C1 inactivator-enzyme interactions. I. Mechanisms of interaction with C1s, plasmin, and trypsin. J. Clin. Invest. 55:593-604.

29. Desrochers, P. E., K. Mookthiar, H. E. Van Wart, K. A. Hasty, and S. J. Weiss. 1992. Proteolytic inactivation of $\alpha 1$-antiproteinase inhibitor and $\alpha 1$-chymotrypsin by oxidatively activated human neutrophil metalloproteinases. $J$. Biol. Chem. 267:5005-5012.

30. Knäuper, V., H. Reinke, and H. Tschesche. 1990. Inactivation of human $\alpha 1$-proteinase inhibitor by human PMN leucocyte collagenase. FEBS (Fed. Eur. Biochem. Soc.) Lett. 263:355-357

31. Knäuper, V., S. Triebel, H. Reinke, and H. Tschesche. 1991. Inactivation of human plasma $\mathrm{Cl}$-inhibitor by human PMN leucocyte matrix metalloproteinases. FEBS (Fed. Eur. Biochem. Soc.) Lett. 290:99-102.

32. Dewald, B., and M. Baggiolini. 1986. Platelet-activating factor as a stimulus of exocytosis in human neutrophils. Biochim. Biophys. Acta. 888:42-48.

33. Niessen, H. W. M., and A. J. Verhoeven. 1992. Differential upregulation of specific and azurophilic granule membrane markers in electropermeabilized neutrophils. Cell. Signalling. In press.

34. Baici, A., and U. Seemuller. 1984. Kinetics of the inhibition of human leucocyte elastase by eglin from the leech Hirudo medicinalis. Biochem. J. 218:829-833.

35. Rao, N. V., N. G. Wehner, B. C. Marshall, W. R. Gray, B. H. Gray, and J. R. Hoidal. 1991. Characterization of proteinase-3 (PR-3), a neutrophil serine proteinase. J. Biol. Chem. 266:9540-9548.

36. Ellis, J. A., S. J. Mayer, and O. T. G. Jones. 1988. The effect of the NAPDH oxidase inhibitor diphenyleneiodonium on aerobic and anaerobic microbicidal activities of human neutrophils. Biochem. J. 251:887-891.

37. Mast, A. E., J. J. Enghild, H. Nagase, K. Suzuki, S. Pizzo, and G. Salvesen. 1991. Kinetics and physiological relevance of the inactivation $\alpha 1$-proteinase inhibitor, $\alpha 1$-antichymotrypsin, and antithrombin III by matrix metalloproteinases-1 (tissue collagenase), -2 (72-kDa gelatinase/type IV collagenase), and -3 (stromelysin). J. Biol. Chem. 266:15810-15816.

38. Lennick, M., S. A. Brew, and K. C. Ingham. 1986. Kinetics of interaction of $\mathrm{C} 1$ Inhibitor with complement C1s. Biochemistry. 25:3890-3898.

39. Sim, R. B., G. J. Arlaud, and M. G. Colomb. 1980. Kinetics of the reaction of human $\mathrm{Cl}$ Inhibitor with the human complement system proteases $\mathrm{Cl} \mathrm{r}$ and C1s. Biochim. Biophys. Acta. 612:433-449.
40. Hortin, G. L., and B. L. Trimpe. 1991. C1 Inhibitor: different mechanisms of reaction with complement component $\mathrm{Cl}$ and $\mathrm{Cls}$. Immunol. Invest. 20:7582.

41. Schapira, M., C. F. Scott, and R. W. Colman. 1981. Protection of human plasma kallikrein from inactivation by $\mathrm{Cl}$ Inhibitor and other protease inhibitors. The role of high molecular weight kininogen. Biochemistry. 20:2738-2743.

42. Holmes, W. E., H. R. Lijnen, and D. Collen. 1987. Characterization of recombinant human $\alpha 2$-Antiplasmin and of mutants obtained by site-directed mutagenesis of the reactive site. Biochemistry. 26:5133-5140.

43. Carrell, R. W. 1986. Alpha-1-antitrypsin: molecular pathology, leukocytes and tissue damage. J. Clin. Invest. 78:1427-1431.

44. Schapira, M., M-A. Ramus, S. Jallat, D. Carvallo, and M. Courtney. 1985. Recombinant $\alpha$ l-antitrypsin Pittsburgh (Met358- > Arg) is a potent inhibitor of plasma kallikrein and activated Factor XII fragment. J. Clin. Invest. 76:635-637.

45. Lawrence, D. A., L. Strandberg, J. Ericson, and T. Ny. 1990. Structurefunction studies of the SERPIN plasminogen activator inhibitor type I. J. Biol. Chem. 265:20293-20301.

46. Skriver, K., W. R. Wikoff, P. A. Patston, F. Tausk, M. Schapira, A. P. Kaplan, and S. C. Bock. 1991. Substrate properties of Cl inhibitor Ma (alanine 434- > glutamic acid). J. Biol. Chem. 266:9216-9221.

47. Carrell, R. W., D. L. Evans, and P. E. Stein. 1991. Mobile reactive centre of serpins and the control of thrombosis. Nature (Lond.). 353:576-578.

48. Bode, W., E. Meyer, and J. C. Powers. 1989. Human leukocyte and porcine pancreatic elastase: X-ray crystal structures, mechanism, substrate specificity, and mechanism-based inhibitors. Biochemistry. 28:1951-1963.

49. Zimmerman, M., and B. M. Ashe. 1977. Substrate specificity of the elastase and the chymotrypsin-like enzyme of the human granulocyte. Biochim. Biophys. Acta. 480:241-245.

50. Nakajima, K., J. C. Powers, B. M. Ashe, and M. Zimmerman. 1979. Mapping the extended substrate binding site of cathepsin $\mathrm{G}$ and human leukocyte elastase. J. Biol. Chem. 254:4027-4032.

51. Powers, J. C., B. F. Gupton, A. D. Harley, N. Nishino, and R. J. Whitley. 1977. Specificity of porcine pancreatic elastase, human leucocyte elastase and cathepsin G. Biochim. Biophys. Acta. 485:156-166.

52. Harper, P. L., D. Evans, and R. W. Carrell. 1991. The potential hazards of antithrombin preparations. Thromb. Haemostasis. 65:914.

53. Desrochers, P. E., J. J. Jeffrey, and S. J. Weiss. 1991. Interstitial collagenase (matrix metalloproteinase-1) expresses serpinase activity. J. Clin. Invest. 87:2258-2265.

54. Chang, N.-S., R. J. Boackle, and R. W. Leu. 1991. Characterization of C1 inhibitor binding to neutrophils. Immunology. 73:95-101. 